\title{
Design of Low Power Mppt with Digital Control for Thermo PV Generator
}

\author{
${ }^{1}$ Shravan Kumar Yadav, ${ }^{2}$ Sweeti Raj, ${ }^{3}$ Shalini Suman, ${ }^{4}$ Shuruti Raj, \\ ${ }^{5}$ M. Madhuri \\ ${ }^{I}$ Shravan Kumar Yadav is currently pursuing B.Tech. degree program(4th year) in Electrical \& Electronics \\ Engineering(EEE) at Apex Institute of Technology \& Management, Bhubaneswar, India. \\ ${ }^{2}$ Sweeti Raj, ${ }^{3}$ Shalini Suman, ${ }^{4}$ Shuruti Raj, ${ }^{5}$ M.Madhuri is currently pursuing B.Tech. degree program (3rd year) \\ in Electronic \& Communication Engineering(ECE) at Apex Institute of Technology \& Management, Bhubanes- \\ war, India.
}

\begin{abstract}
The need for renewable energy sources is on the rise because of the acute energy crisis in the world today. This describes the design, optimization, and evaluation of the power electronics circuitry for a low-power portable thermophotovotaic (TPV) generator system in mat lab. TPV system is based on a silicon micro-reactor design and low-band gap photovoltaic $(P V)$ diodes. We outline critical system-level challenges associated with TPV power generation, and propose a power electronics architecture that addresses these challenges. We present experimental data from a compact, highly efficient peak power tracker and show how the proposed architecture enables increased energy extraction compared to conventional methods. The operation of the power tracker is verified with low-band gap PV cells illuminated by a quartz halogen lamp producing a PV diode output power of $0.5 \mathrm{~W}$, and above $99 \%$ tracking efficiency is demonstrated. Additionally, the complete system operation is verified with the power tracker connected to GaInAsSb PV diodes silicon and a micro-reactor, producing $150 \mathrm{~mW}$ of electrical power.

Keywords : Photovoltaic, Fuzzy logic control, MPPT, Boost Converter, Neural Network.
\end{abstract}

\section{INTRODUCTION}

A Thermo photovoltaic generator (TPV) is an innovative system able to convert the radiant energy of combustion into electrical energy. This conversion is realized by using photovoltaic cells. A scheme of a TPV is presented in Figure 1.1, in which the main components and energy flows are highlighted. A TPV generator consists of a heat source, an emitter (EM), a filter (F) and an array of photovoltaic cells (PV); the combustion air pre-heating system which uses the combustion products is also sketched in Fig. 1.1. The thermal production of the TPV is realized by the heat exchangers which respectively recover the heat from the cooling of PV cells and the exhaust combustion products. The main advantages of this energy system can be found in the

(i) High fuel utilization factor .

(ii) Low produced noise levels (due to the absence of moving parts).

(iii) Easy maintenance (similar to a common domestic boiler)

(iv) Great fuel flexibility.

In fact, with this regard, it can be observed that the heat source of a TPV system can be provided by various fuel typologies such as fossil fuels (natural gas, oil, coke, etc.) municipal solid wastes, nuclear fuels, etc; concentrated solar radiation can also be used as a TPV heat source. A TPV system usually allows very low pollutant emissions (e.g. $\mathrm{CO}$ and $\mathrm{NOx}$ ), since it is often coupled with combustion devices such as domestic boilers.

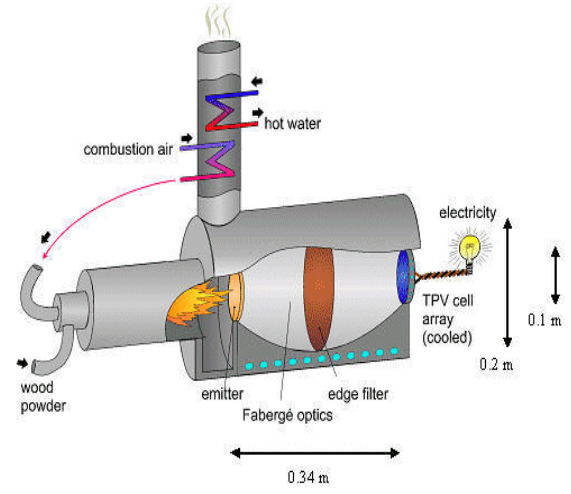

Figure 1.1: Thermophotovoltaic generator system 
In fact, with this regard, it can be observed that the heat source of a TPV system can be provided by various fuel typologies such as fossil fuels (natural gas, oil, coke, etc.) municipal solid wastes, nuclear fuels, etc; concentrated solar radiation can also be used as a TPV heat source. A TPV system usually allows very low pollutant emissions (e.g. $\mathrm{CO}$ and NOx), since it is often coupled with combustion devices such as domestic boilers.

The main use of a TPV generator can be in the distributed combined heat and power generation, but its application in the automotive sector in case of hybrid vehicles, glass or other high temperatures industries has also been analyzed in literature. The TPV system has been proposed for portable generators, co-generation systems, combined cycle power plants, solar power plants, grid connected or independent equipment. Other studies show the integration of TPV generator with thermoelectric systems or with Organic Rankine Cycles. Further studies were developed in military and space sectors.

\subsection{Thermo Photovoltaic cell}

\section{Standalone Thermo Photovoltaic System}

A thermo photovoltaic cell or photoelectric cell is a semiconductor device that converts light to electrical energy by photovoltaic effect. If the energy of photon of light is greater than the band gap then the electron is emitted and the flow of electrons creates current.

However a thermo photovoltaic cell is different from a photodiode. In a photodiode light falls on $\mathrm{n}$ channel of the semiconductor junction and gets converted into current or voltage signal but a photovoltaic cell is always forward biased.

\subsubsection{TPV MATERIALS}

Three different materials were used in the design of this model. These materials were chosen for their Eg to cover as much of the expected IR radiation spectrum as possible. InGaN, Indium Nitride (InN), and Indium Arsenide (InAs) all have lower Eg and are intended to absorb different portions of the IR radiation.

\subsection{Thermo PV module}

Usually a number of PV modules are arranged in series and parallel to meet the energy requirements. PV modules of different sizes are commercially available (generally sized from 60W to $170 \mathrm{~W})$. For example, a typical small scale desalination plant requires a few thousand watts of power.

\subsubsection{Materials used in thermo photovoltaics solar Panels}

The basic building block of a photovoltaic solar system is the solar cell. Solar cells are solid state, semiconductor devices that convert sunlight into electricity. Typically a number of individual cells are connected together to form modules, or solar panels. In order to provide electrical insulation and protect against environmental corrosion, the solar cells are encased in a transparent material referred to as an encapsulant.

To provide structural integrity the solar cells are mounted on top of a rigid flat surface or substrate. A transparent cover film, commonly glass, further protects these components from the elements. Several types of semiconductor materials are used to manufacture solar cells but the most common material is crystalline silicon, typically from quartz or sand, capturing a $60 \%$ market share.4 Crystalline silicon semiconductors are also utilized in the manufacture of integrated circuits and microchips used in personal computers, cellular telephones and other modern electronics. The outer glass cover constitutes the largest share of the total mass of a finished crystalline photovoltaic module (approximately $65 \%$ ), followed by the aluminum frame $(\sim 20 \%)$, the ethylene vinyl acetate encapsulant $(\sim 7.5 \%)$, the polyvinyl fluoride substrate $(\sim 2.5 \%)$, and the junction box $(1 \%)$. The solar cells themselves only represent about four percent $(4 \%)$ of the mass of a finished module.

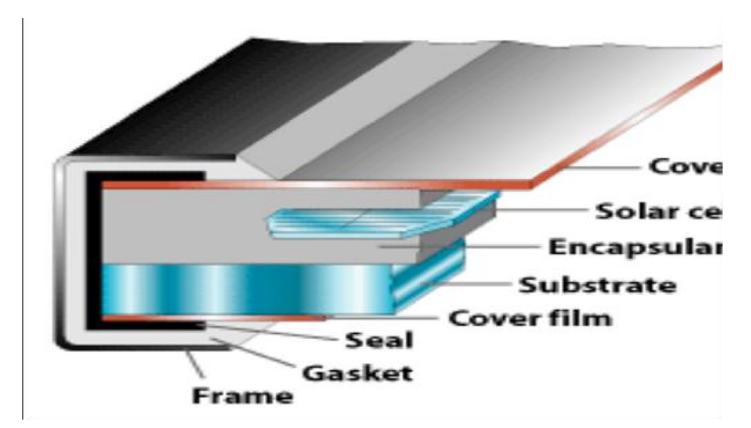

Figure 2.1: Different layer of TPV panel

\subsubsection{Thermal Infrared Imaging of module}

Thermal infrared (IR) imaging provided a convenient and non-destructive means for identifying locations in modules where the series resistance was atypically high. The procedure involved connecting a module 
to a power supply with the module in a forward-biased condition, as in a dark I-V measurement. The power supply was then set to provide continuous current through the module at a level approximately two times the nameplate short-circuits current. As the module heated up, IR images were recorded using a FLIR Systems (Prism DS IR) camera with wavelength sensitivity in the range of 3.6 to 5.0 microns.

\subsection{Thermo PV modeling}

A PV array consists of several photovoltaic cells in series and parallel connections. Series connections are responsible for increasing the voltage of the module whereas the parallel connection is responsible for increasing the current in the array. Typically a solar cell can be modeled by a current source and an inverted diode connected in parallel to it. It has its own series and parallel resistance. Series resistance is due to hindrance in the path of flow of electrons from $n$ to $p$ junction and parallel resistance is due to the leakage current.

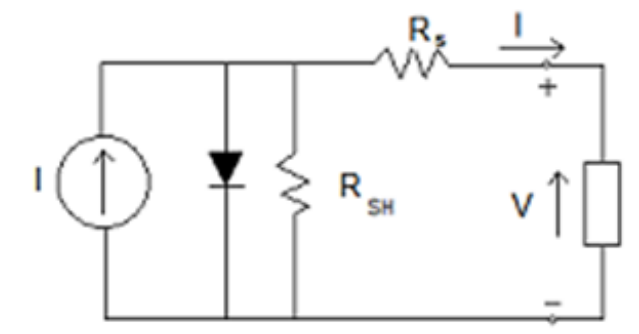

Figure 2.2: Single diode model of a PV cell

In this model we consider a current source (I) along with a diode and series resistance (Rs). The shunt resistance $\left(\mathrm{R}_{\mathrm{SH}}\right)$ in parallel is very high, has a negligible effect and can be neglected.

The output current from the photovoltaic array is

$I=I_{s c}-I_{d}$

$$
I_{d}=I_{0}\left(e^{\frac{q V_{d}}{K T}}-1\right)
$$

Where $I_{0}$ is the reverse saturation current of the diode, $\boldsymbol{q}$ is the electron charge, $\boldsymbol{V}_{d}$ is the voltage across the diode, ${ }^{K}$ is Boltzmann constant $\left(1.38=10^{-19} \mathrm{~J} / \mathrm{K}\right)$ and $T$ is the junction temperature in Kelvin $(\mathrm{K})$ From eq. 3.1 and 3.2

$$
I=I_{s c}-I_{0}\left(e^{\frac{q V}{K T}}-1\right)
$$

Using suitable approximations,

$$
I=I_{s c}-I_{0}\left(e^{\frac{q\left[V+I R_{s}\right]}{n K T}}-1\right)
$$

Where, $\boldsymbol{I}$ is the photovoltaic cell current, $\boldsymbol{V}$ is the PV cell voltage, $\boldsymbol{T}$ is the temperature (in Kelvin) and $\boldsymbol{n}$ is the diode ideality factor.

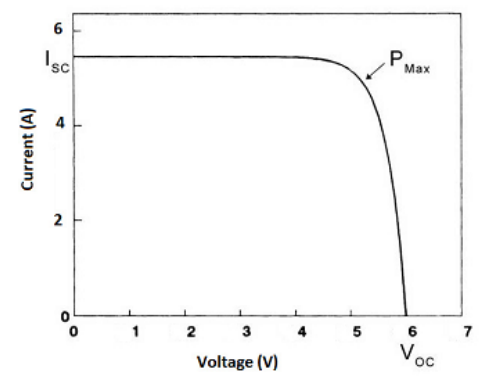

Figure 2.3: I-V characteristics of a typical solar panel 
When the voltage and the current characteristics are multiplied we get the P-V characteristics as shown in figure 3.4. The point indicated as MPP is the point at which the panel power output is maximum.

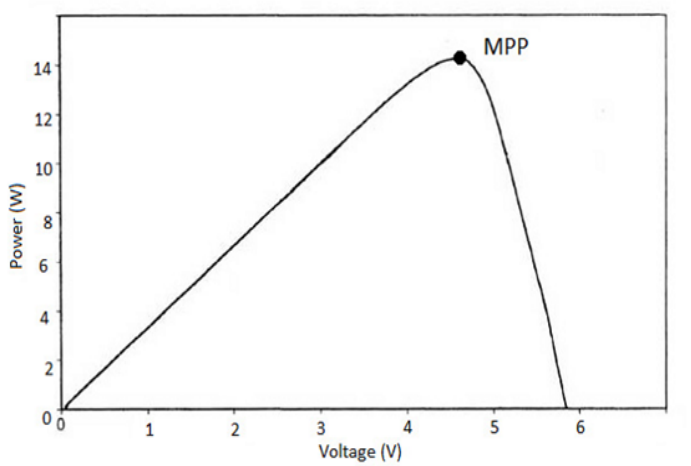

Figure 2.4: P-V characteristics curve of photovoltaic cell

\subsection{Boost Converter}

\section{CONVERTER}

As stated in the introduction, the maximum power point tracking is basically a load matching problem. In order to change the input resistance of the panel to match the load resistance (by varying the duty cycle), a DC to DC converter is required. It has been studied that the efficiency of the DC to DC converter is maximum for a buck converter, then for a buck-boost converter and minimum for a boost converter but as we intend to use our system either for tying to a grid or for a water pumping system which requires $230 \mathrm{~V}$ at the output end, so we use a boost converter.

\subsection{Design of Boost converter}

A boost converter is part of a subset of DC-DC converters called switch-mode converters. The circuits belonging to this class, including buck, flyback, buck-boost, and push-pull converters are very similar. They generally perform the conversion by applying a DC voltage across an inductor or transformer for a period of time (usually $100 \mathrm{kHz}-5 \mathrm{MHz}$ range) which causes current to flow through it and store energy magnetically, then switching this voltage off and causing the stored energy to be transferred to the voltage output in a controlled manner.

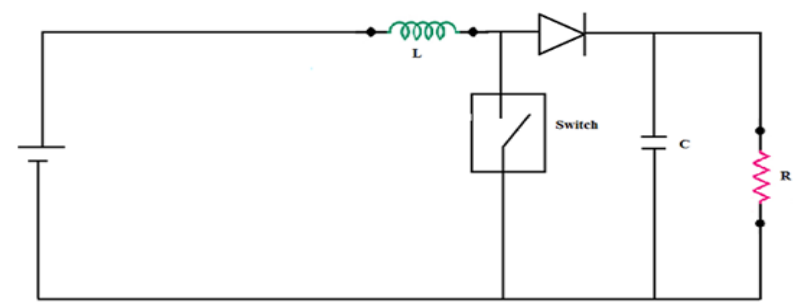

Figure 3.1: Circuit diagram of a Boost Converter

The output voltage is regulated by adjusting the ratio of on/off time. The efficiencies are seen in the 80-95\% range. This is clearly desirable, as it increases the running time of battery-operated devices. The basic boost converter circuit consists of only a switch (typically a transistor), a diode, an inductor, and a capacitor. The specific connections are shown in figure 3.1.

\section{MaXimum Power Point Tracking Control}

\subsection{An overview of Maximum Power Point Tracking}

A typical solar panel converts only 30 to 40 percent of the incident solar irradiation into electrical energy. Maximum power point tracking technique is used to improve the efficiency of the solar panel. According to Maximum Power Transfer theorem, the power output of a circuit is maximum when the Thevenin impedance of the circuit (source impedance) matches with the load impedance. Hence our problem of tracking the maximum power point reduces to an impedance matching problem.

In the source side we are using a boost convertor connected to a solar panel in order to enhance the output voltage so that it can be used for different applications like motor load. By changing the duty cycle of the boost con- 
verter appropriately we can match the source impedance with that of the load impedance.

4.2 Different MPPT techniques

There are different techniques used to track the maximum power point. Few of the most popular techniques are:

1) Perturb and Observe (hill climbing method)

2) Incremental Conductance method

3) Fractional short circuit current

4) Fractional open circuit voltage

5) Neural networks

6) Fuzzy logic

The choice of the algorithm depends on the time complexity the algorithm takes to track the MPP, implementation cost and the ease of implementation.

\subsubsection{Perturb \& Observe}

Perturb \& Observe $(\mathrm{P} \& \mathrm{O})$ is the simplest method. In this we use only one sensor, that is the voltage sensor, to sense the PV array voltage and so the cost of implementation is less and hence easy to implement. The time complexity of this algorithm is very less but on reaching very close to the MPP it doesn't stop at the MPP and keeps on perturbing on both the directions. When this happens the algorithm has reached very close to the MPP and we can set an appropriate error limit or can use a wait function which ends up increasing the time complexity of the algorithm.

However the method does not take account of the rapid change of irradiation level (due to which MPPT changes) and considers it as a change in MPP due to perturbation and ends up calculating the wrong MPP. To avoid this problem we can use incremental conductance method.

\subsubsection{Incremental Conductance}

Incremental conductance method uses two voltage and current sensors to sense the output voltage and current of the PV array.

At MPP the slope of the PV curve is 0.

$$
\begin{aligned}
& (d P / d V)_{M P P}=d(V I) / d V \\
& 0=I+V d I / d V_{M P P} \\
& \frac{d I}{d V_{M P P}}=-I / V
\end{aligned}
$$

The left hand side is the instantaneous conductance of the solar panel. When this instantaneous conductance equals the conductance of the solar then MPP is reached.

Here we are sensing both the voltage and current simultaneously. Hence the error due to change in irradiance is eliminated. However the complexity and the cost of implementation increases. As we go down the list of algorithms the complexity and the cost of implementation goes on increasing which may be suitable for a highly complicated system. This is the reason that Perturb and Observe and Incremental Conductance method are the most widely used algorithms. Owing to its simplicity of implementation we have chosen the Perturb \& Observe algorithm for our study among the two.

\subsubsection{Fractional open circuit voltage}

The near linear relationship between VMPP and VOC of the PV array, under varying irradiance and temperature levels, has given rise to the fractional VOC method.

$$
V_{\text {MPP }}=K_{1} V_{\text {oc }}
$$

Where $K_{1}$ is a constant of proportionality. Since $K_{1}$ is dependent on the characteristics of the PV array being used, it usually has to be computed beforehand by empirically determining $\boldsymbol{V}_{\text {MPP }}$ and $V_{\text {OC }}$ for the specific PV array at different irradiance and temperature levels. The factor $K_{1}$ has been reported to be between 0.71 and 0.78 . Once $\boldsymbol{K}_{1}$ is known, $\boldsymbol{V}_{\text {MPP }}$ can be computed with $\boldsymbol{V}_{\text {oc }}$ measured periodically by momentarily shutting down the power converter. However, this incurs some disadvantages, including temporary loss of power. 


\subsubsection{Fractional short circuit current}

Fractional $\mathrm{I}_{\mathrm{SC}}$ results from the fact that, under varying atmospheric conditions, IMPP is approximately linearly related to the $\mathrm{I}_{\mathrm{SC}}$ of the PV array.

$I_{M P P}=K_{2} I_{s c}$

Where $\boldsymbol{K}_{2}$ is a proportionality constant. Just like in the fractional $\boldsymbol{V}_{\text {oc }}$ technique, $\boldsymbol{K}_{2}$ has to be determined according to the PV array in use. The constant $\boldsymbol{K}_{2}$ is generally found to be between 0.78 and 0.92. Measuring $\boldsymbol{I}_{s c}$ during operation is problematic. An additional switch usually has to be added to the power converter to periodically short the PV array so that ISC can be measured using a current sensor.

\subsubsection{Fuzzy Logic Control}

Microcontrollers have made using fuzzy logic control popular for MPPT over last decade. Fuzzy logic controllers have the advantages of working with imprecise inputs, not needing an accurate mathematical model, and handling nonlinearity.

\subsubsection{Neural Network}

Another technique of implementing MPPT which are also well adapted for microcontrollers is neural networks. Neural networks commonly have three layers: input, hidden, and output layers. The number nodes in each layer vary and are user-dependent.

The input variables can be PV array parameters like $\boldsymbol{V}_{\text {oc }}$ and $\boldsymbol{I}_{s c}$, atmospheric data like irradiance and temperature, or any combination of these. The output is usually one or several reference signals like a duty cycle signal used to drive the power converter to operate at or close to the MPP.

Table 1: Characteristics of different MPPT techniques

\begin{tabular}{|c|c|c|c|c|}
\hline MPPT technique & $\begin{array}{c}\text { Convergence } \\
\text { speed }\end{array}$ & $\begin{array}{c}\text { Implementation } \\
\text { complexity }\end{array}$ & $\begin{array}{c}\text { Periodic } \\
\text { tuning }\end{array}$ & Sensed parameters \\
\hline Perturb \& observe & Varies & Low & No & Voltage \\
\hline $\begin{array}{l}\text { Incremental } \\
\text { conductance }\end{array}$ & Varies & Medium & No & Voltage, current \\
\hline Fractional $V_{\propto}$ & Medium & Low & Yes & Voltage \\
\hline Fractional $\mathrm{I}_{\mathrm{sc}}$ & Medium & Medium & Yes & Current \\
\hline Fuzzy logic control & Fast & High & Yes & Varies \\
\hline Neural network & Fast & High & Yes & \begin{tabular}{|l} 
Varies \\
\end{tabular} \\
\hline
\end{tabular}

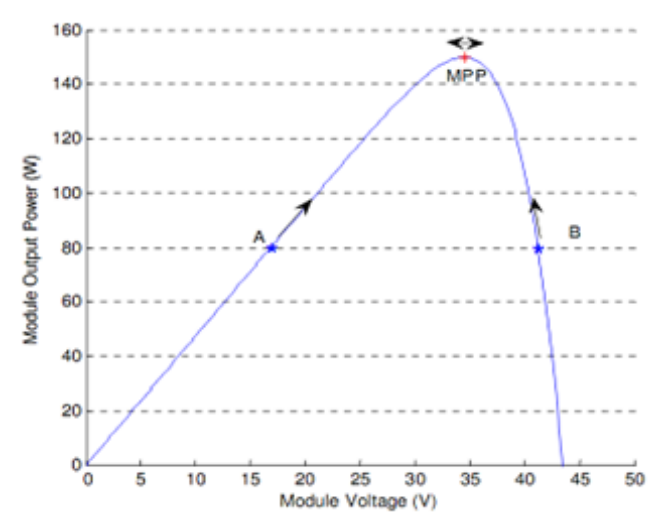

Figure 4.1: Solar panel characteristics showing MPP and operating points A and B

\subsection{Implementation of MPPT using a boost con verter}

The system uses a boost converter to obtain more practical uses out of the solar panel. The initially low voltage output is stepped up to a higher level using the boost converter, though the use of the converter does tend to introduce switching losses. 
The block diagram shown in figure 5.2 gives an overview of the required implementation

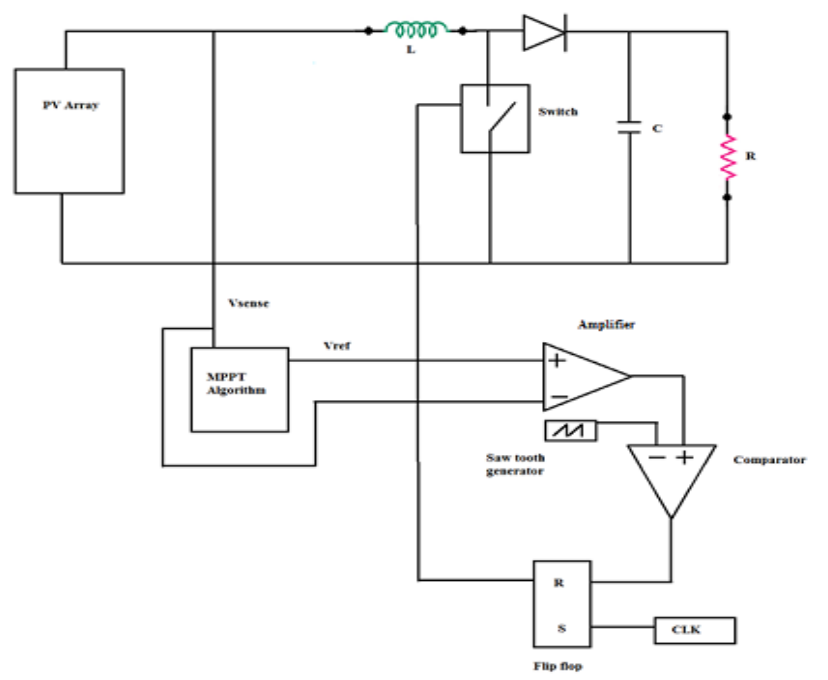

Figure 4.2: Requisite implementation for MPPT system

\subsection{Solar panel}

\section{Modeling Of Standalone Pv System}

The entire system has been modeled on MATLAB ${ }^{\mathrm{TM}}$ 2009a and Simulink ${ }^{\mathrm{TM}}$. The block diagram of the solar PV panel is shown in Figure 5.1 and Figure 5.2. The inputs to the solar PV panel are temperature, solar irradiation, number of solar cells in series and number of rows of solar cells in parallel.

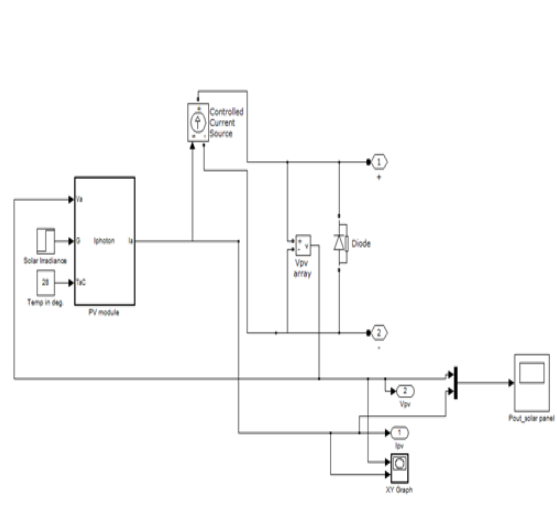

Figure 5.1: Block diagram of the modeled solar PV panel

\subsection{MPPT Interfacing}

The controlled voltage source and the current source inverter have been used to interface the modeled panel with the rest of the system and the boost converter which are built using the SimPowerSystems module of MATLAB. The block diagram for the model shown in figure 5.2 is a simulation for the case where we obtain a varying voltage output. This model is used to highlight the difference between the power obtained on using an MPPT algorithm and the power obtained without using an MPPT algorithm.

To compare the power output in both the cases stated above, the model is equipped with a manual switch as shown. When the switch is thrown to the left the circuit bypasses the MPPT algorithm and we obtain the desired power, voltage and current outputs through the respective scopes. Contrarily when the switch is thrown to the right, the embedded MPPT function block is included in the circuit and we obtain the desired outputs through the respective scopes.

\subsection{Boost Converter}

A boost converter has been used in our simulation. It finds applications in various real life scenarios like charging of battery bank, running of DC motors, solar water pumping etc. The simulation has been done for a resistive load of $300 \Omega$. For efficient running of a motor, we should undergo load resistance matching techniques. In the boost converter circuit, the inductor has been chosen to be $0.763 \mathrm{mH}$ and the capacitance is taken to be $0.611 \mu \mathrm{F}$ for a ripple free current. 


\subsection{PI Controller}

The system also employs a PI controller. The task of the MPPT algorithm is just to calculate the reference voltage Vref towards which the PV operating voltage should move next for obtaining maximum power output. This process is repeated periodically with a slower rate of around 1-10 samples per second. The external control loop is the PI controller, which controls the input voltage of the converter. The pulse width modulation is carried in the PWM block at a considerably faster switching frequency of $100 \mathrm{KHz}$.

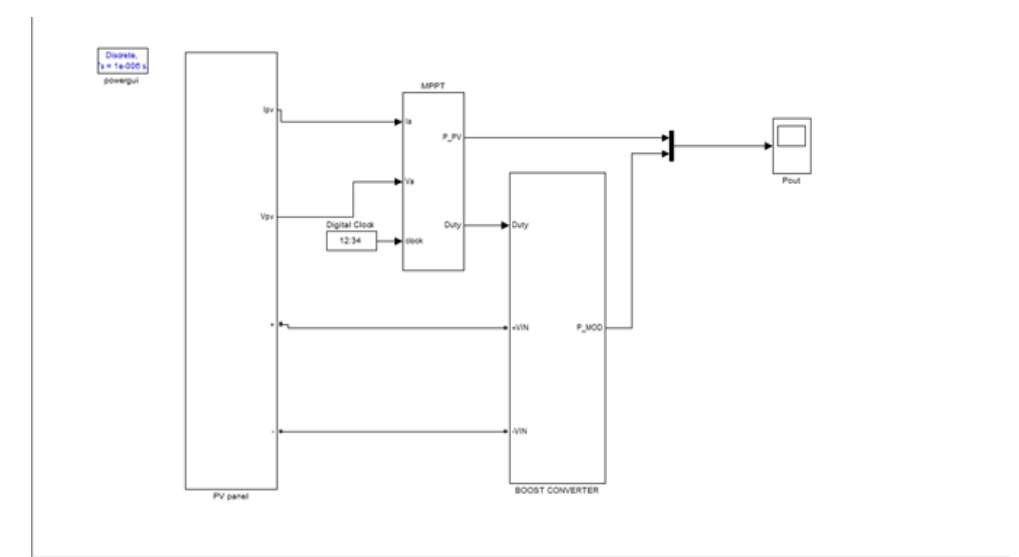

Figure 5.2: SIMULINK ${ }^{\text {MM }}$ Model of MPPT system using P\&O algorithm

In our simulation, KP is taken to be 0.006 and $\mathrm{KI}$ is taken to be 7. A relatively high KI value ensures that the system stabilizes at a faster rate. The PI controller works towards minimizing the error between Vref and the measured voltage by varying the duty cycle through the switch. The switch is physically realized by using a MOSFET with the gate voltage controlled by the duty cycle.

Table 2: Different parameters of the standalone PV system

\begin{tabular}{|c|c|}
\hline Parameter & Value taken for simulation \\
\hline Solar Module Temperature (T) & $28^{\circ} \mathrm{C}$ \\
\hline No of solar cells in series ( $\left.\mathbf{N}_{\mathbf{v}}\right)$ & 60 \\
\hline No of rows of solar cells in parallel ( $\left.\mathbf{N}_{\mathrm{p}}\right)$ & 4 \\
\hline Resistance of load (R) & $300 \Omega$ \\
\hline Capacitance of boost converter (C) & $0.611 \mu \mathrm{F}$ \\
\hline Inductance of boost converter (L) & $0.763 \mathrm{mH}$ \\
\hline Switching frequency of PWM & $100 \mathrm{KHz}$ \\
\hline Proportional gain of P1 controller $\left(\boldsymbol{K}_{\mathbf{p}}\right)$ & 0.006 \\
\hline Integral gain of Pl controller $\left(\mathbf{K}_{\mathbf{1}}\right)$ & 7 \\
\hline
\end{tabular}

\subsection{Running the system with MPPT}

\section{RESULTS}

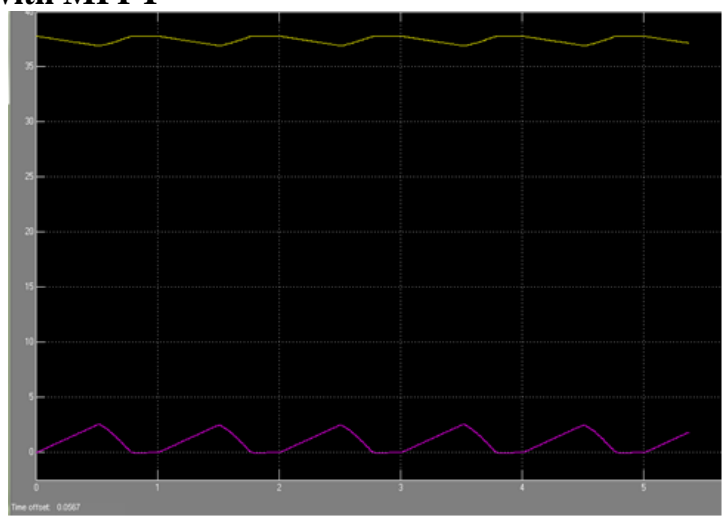

Figure 6.1: Plot of Output Power of PV panel v/s time 


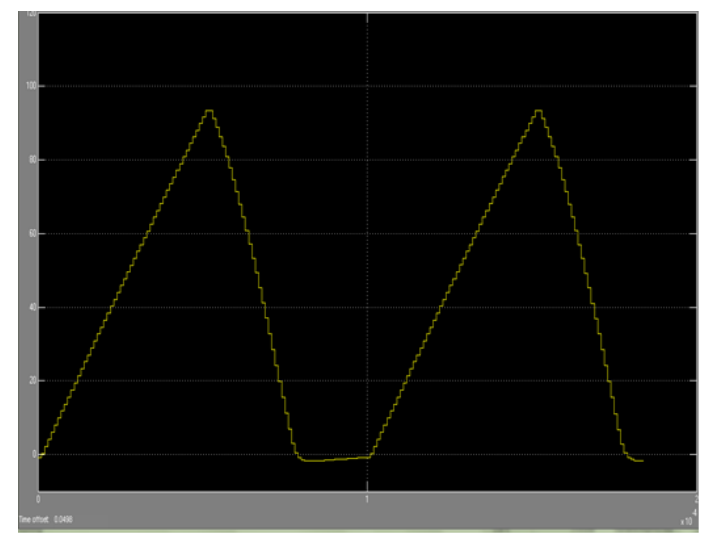

Figure 6.2: Plot of Power output of MPPT v/s time

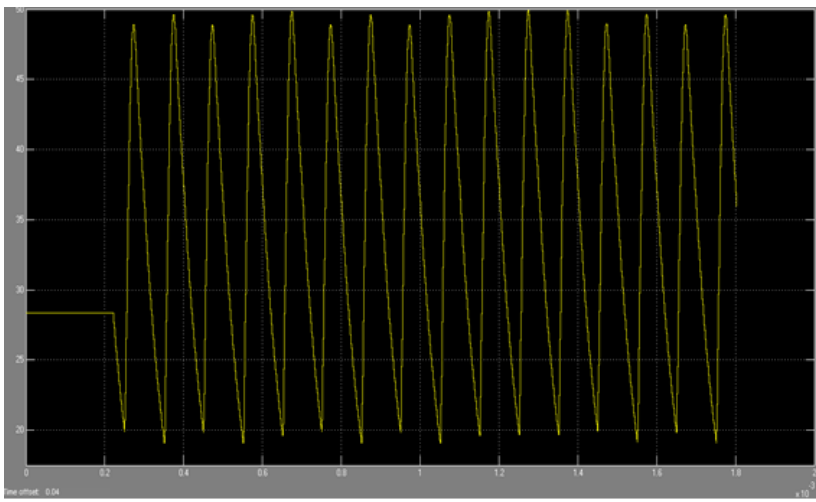

Figure 6.3: Plot of Output Power of Boost Converter v/s time

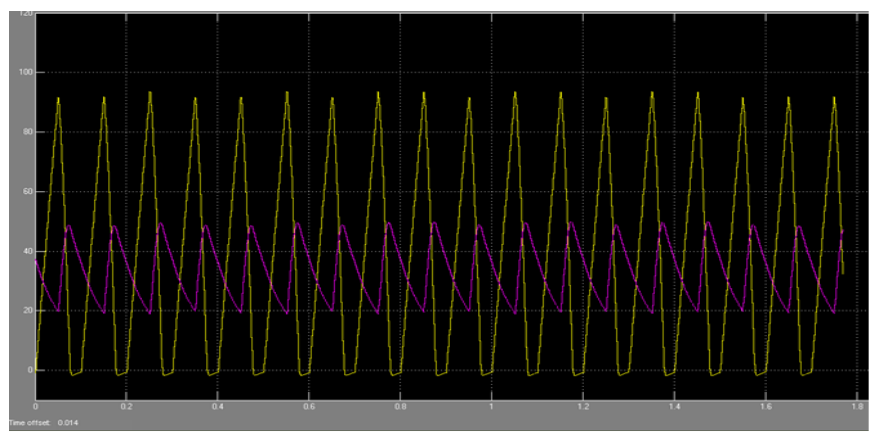

Figure 6.4: Plot of Output Power at load side v/s time

\section{Conclusion}

The model shown in Figure 6.2 was simulated using SIMULINK and MATLAB. The plots obtained in the different scopes have been shown in Chapter 7. The simulation was first run with the switch on no MPPT mode, bypassing the MPPT algorithm block in the circuit. It was seen that when we do not use an MPPT algorithm, the power obtained at the load side was around 95 Watts (Figure 7.4) for a solar irradiation value of 85 Watts per sq. cm. It must be noted that the PV panel generated around 250 Watts power (Figure 7.1) for this level of solar irradiation. Therefore, the conversion efficiency came out to be very low.

\section{References}

[1]. Muhida, R., Park, M., Dakkak, M., Matsuura, K., Tsuy oshi, A., Michira, M., 2003. A maximum power point tracking for photovoltaic-SPE system using a maxi mum current controller. Solar Energy Materials and Solar Cells 75, 697-706.

[2]. Atmel, "AVR121: Enhancing ADC resolution by over sampling," application note, 2005.

[3]. H. Kolm, "Solar-battery power source," quarterly pro gress report, solid state research, group 35, MIT-Lincoln laboratory, 1956.

[4]. T. Esram and P. Chapman, "Comparison of photovolta ic array maximum power point tracking techniques," IEEE Transaction on Energy Conversion, vol. 22, no. 2, pp. 439-449, 2007. 
[5]. Hua, C., Lin, J., 2003. An on-line MPPT algorithm for rapidly changing illuminations of solar arrays. Journal of Renewable Energy.

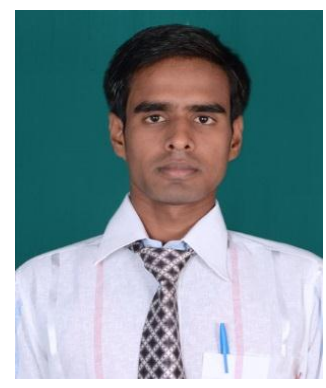

Shravan Kumar Yadav S/O Dr. Sheo Bhajan Ram Yadav was born in (Jharkhand) in India, on April, 1992. He is currently pursuing B.Tech. Degree program (4th year) in Electrical \& Electronics Engineering (EEE) at Apex Institute of Technology \& Management, Bhubaneswar, India. He has published more than two research papers and successfully completed his four weeks industrial training from 09 June 2013 to 10 July 2013 at NALCO, Angul, India (A Government of India Enterprise), India, PH-+ 91-9040316409. (E-mail: callshravanjsr@gmail.com).

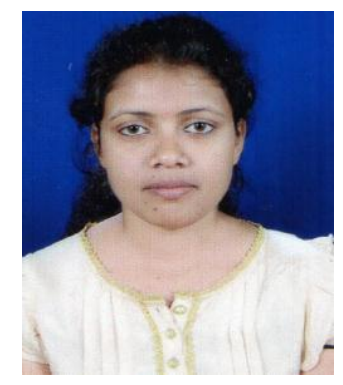

Sweeti Raj D/O Mr. Chandra Deo Yadav was born in (Bihar) in India, on April, 1993. She is currently pursuing B.Tech. Degree program ( $3^{\text {rd }}$ year) in Electronics \& Communication Engineering (ECE) at Apex Institute of Technology \& Management, Bhubaneswar, India. She has successfully completed her industrial training at BSNL, India and VLSI ceritified. (E-mail: sweeti123razz@gmail.com).

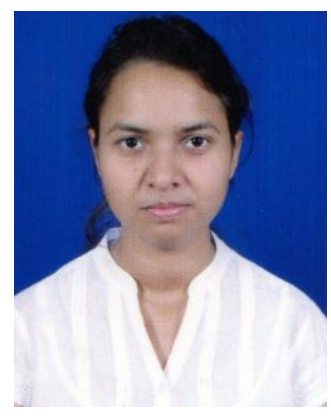

Shalini Suman D/O Mr. Bhagwan Singh was born in (Jharkhand) in India, on May, 1993. She is currently pursuing B.Tech. Degree program ( $3^{\text {rd }}$ year) in Electronics \& Communication Engineering (ECE) at Apex Institute of Technology \& Management, Bhubaneswar, India. She has successfully completed her industrial training at BSNL, India and VLSI ceritified. (E-mail: sumanshalini279@gmail.com).

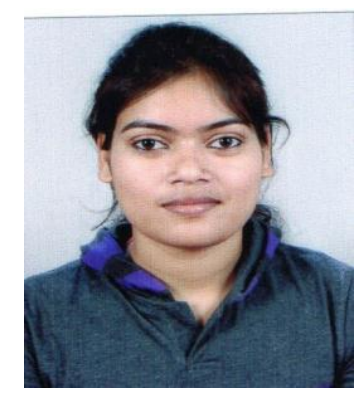

Shuruti Raj D/O Mr. Chandra Deo Yadav was born in (Bihar) in India, on June, 1993. She is currently pursuing B.Tech. Degree program ( $3^{\text {rd }}$ year) in Electronics \& Communication Engineering (ECE) at Apex Institute of Technology \& Management, Bhubaneswar, India. She has successfully completed her industrial training at BSNL, India and VLSI ceritified (Email: shurutiraj14@gmail.com).

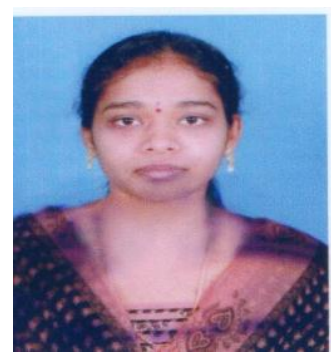

M.Madhuri D/O Mr. M.Appa Rao was born in (Odisha) in India, on March, 1993. She is currently pursuing B.Tech. Degree program $\left(3^{\text {rd }}\right.$ year $)$ in Electronics \& Communication Engineering (ECE) at Apex Institute of Technology \& Management, Bhubaneswar, India. She has successfully completed her industrial training at BSNL, India and VLSI ceritified (E-mail: mechatemadhuri@gmail.com). 